\title{
The Influence of Non-Host Predators on Parasite-Induced Behavioral Changes in a
} Freshwater Snail

\author{
Edward P. Levri \\ Oikos, Vol. 81, No. 3. (Apr., 1998), pp. 531-537.
}

Stable URL:

http://links.jstor.org/sici?sici=0030-1299\%28199804\%2981\%3A3\%3C531\%3ATIONPO\%3E2.0.CO\%3B2-3

Oikos is currently published by Nordic Society Oikos.

Your use of the JSTOR archive indicates your acceptance of JSTOR's Terms and Conditions of Use, available at http://www.jstor.org/about/terms.html. JSTOR's Terms and Conditions of Use provides, in part, that unless you have obtained prior permission, you may not download an entire issue of a journal or multiple copies of articles, and you may use content in the JSTOR archive only for your personal, non-commercial use.

Please contact the publisher regarding any further use of this work. Publisher contact information may be obtained at http://www.jstor.org/journals/oikos.html.

Each copy of any part of a JSTOR transmission must contain the same copyright notice that appears on the screen or printed page of such transmission.

JSTOR is an independent not-for-profit organization dedicated to and preserving a digital archive of scholarly journals. For more information regarding JSTOR, please contact support@jstor.org. 


\title{
The influence of non-host predators on parasite-induced behavioral changes in a freshwater snail
}

\author{
Edward P. Levri
}

Levri, E. P. 1997. The influence of non-host predators on parasite-induced behavioral changes in a freshwater snail. - Oikos 81: 531-537.

\begin{abstract}
Parasites can have striking influences on their host's behavior that serve to increase the probability of parasite transmission. The type of behavior induced often increases the probability of an encounter with the next host in the life cycle. However non-host predators could also serve as selective forces on the manipulative strategy of the parasite. In this study, I examined the daily foraging behavior of a New Zealand fish (Gobiomorphus cotidianus), and related it to the foraging habits of a snail (Potamopyrgus antipodarum) infected with the trematode Microphallus sp. Previous results have demonstrated that Microphallus alters the snails' behavior in a time-specific manner: infected individuals forage on the top of rocks late into the morning, when the final host (waterfowl) is feeding most, and then move to the bottom of the rocks. Since waterfowl continue to forage (albeit at a lower rate) throughout the day, the infected snails' movement to the bottom of the rocks is perplexing. Here I examined the gut contents of fish collected at different times of the day. I found that fish feed on snails predominantly in the late morning to early afternoon hours, which corresponds to the time that infected snails move to the bottom of the rocks. I also found that snails taken from fish guts are less likely to be infected by Microphallus than snails from the overall population. Thus it would appear that the behavior induced by Microphallus decreases the probability that an infected snail will be eaten by an unsuitable host.
\end{abstract}

E. P. Levri, Dept of Biology, Indiana Univ., Bloomington, IN 47405, USA (elevri@sunflower.bio.indiana.edu).

Parasites often alter the behavior of their hosts in ways that increase the probability of parasite transmission (for reviews see Holmes and Bethel 1972, Dobson 1988, Moore and Gotelli 1990). Behavioral alterations of this type are commonly (but not exclusively) associated with parasites that have more than one host in their life cycle and need to be eaten in order for transmission to occur (Holmes and Bethel 1972). Thus, in many cases, the effect of the behavioral change is to increase the probability of predation by the next host in the life cycle.

In some cases, however, it may be more beneficial for the parasite if its host avoids predation. Avoiding predation would be advantageous when the parasite is not sufficiently developed for successful establishment in the final host. In this case it would be beneficial for the parasite to avoid all predators, including the final host. There are several examples of behavioral manipulation where induced behavioral changes do not occur until the parasite is transmissible (Bethel and Holmes 1974, Hurd and Fogo 1991, Granovitch 1992, Poulin et al. 1992, Tierney et al. 1993, Levri and Lively 1996). Non-transmissible parasites may also benefit from altering the behavior of their host. Tierney et al. (1993) present data that are consistent with the idea that non-transmissible parasites may induce predatoravoidance behaviors. Although the aim of their study was not specifically to address this idea, their data suggest that non-transmissible cestode plerocercoids increase the recovery time to a predator attack, decrease the duration of pectoral sculling, and increase

Accepted 19 September 1997

Copyright (C) OIKOS 1998

ISSN 0030-1299

Printed in Ireland - all rights reserved 
the time spent motionless of three-spined sticklebacks compared to uninfected controls. Tierney et al. (1993) suggest that these behaviors seem to decrease the probability of predation on the fish.

Avoiding predation may also be advantageous for the parasite even when the parasite is transmissible, because changes in host behavior may increase exposure not only to the next host in the life cycle, but also to predators that cannot serve as a host. In situations where the next host in the life cycle is not the most common predator, it may be beneficial for the parasite to induce behaviors that decrease the probability of predation. This situation seems most probable when the chance of encounter with the final host and/or the other predators is variable in time or space. For example, if the final host is most active during the summer, but other predators are active all year long, it may be better for the parasite to induce predation-enhancing behavior only in the summer. One may also expect the parasite to induce behaviors to avoid predation the rest of the year under certain circumstances.

Behavioral changes that effectively decrease predation while the parasite is transmissible may occur in the snail Potamopyrgus antipodarum infected by the trematode parasite Microphallus sp. Microphallus alters the behavior of its intermediate host, $P$. antipodarum, in a way that appears to increase its probability of transmission to the final host, waterfowl (Levri and Lively 1996). The parasite causes the snail to remain on the top of rocks (where they are exposed to predators) in the early morning hours when waterfowl forage most; while most uninfected classes of snails move to the bottom of the rocks. However, Microphallus-infected snails move to the bottom of the rocks in the late morning. This is somewhat anomalous because waterfowl continue to forage into the afternoon hours, although less frequently. If increased exposure to waterfowl were the only influence on the parasite's manipulative strategy, then the snails should remain on top of the rocks throughout the day. To explain this movement by snails to the bottom of the rocks, it is possible that other predators (e.g. fish) which cannot serve as final hosts feed on snails predominantly in the late morning and early afternoon. If Microphallus were ingested by fish, the parasite would die. Thus, I hypothesized that Microphallus induces the snail to move to the bottom of the rocks during the late morning to avoid being eaten by an unsuitable host.

Here I demonstrate that fish feed on snails in the late morning and early afternoon more than in the early morning hours. Further, snails ingested by the fish Gobiomorphus cotidianus are less likely to be infected by Microphallus than snails from the population at large. This result suggests that the behavior induced by $\mathrm{Mi}$ crophallus in the late morning (movement to the bottom of the rocks) reduces the probability that infected snails will be eaten by an unsuitable host.

\section{The system of study}

Potamopyrgus antipodarum is a small prosobranch gastropod found in many New Zealand lakes and streams. The snail feeds on green algae, diatoms and detritus (Winterbourn 1970, Haynes and Taylor 1984, Winterbourn and Fegley 1989). In rocky habitats the snails forage on top of rocks for algae predominantly at night (Levri and Lively 1996). The most common predator of $P$. antipodarum in many places is the fish Gobiomorphus cotidianus (the common bully). The diet of the fish consists of zooplankton, insect larvae, and several species of molluscs, including $P$. antipodarum (McDowall 1990).

Microphallus sp. is the predominant parasite of $P$. antipodarum (Lively 1987), and it has a two-host life cycle. Adult worms reproduce sexually in waterfowl, and eggs are expelled into the water with the feces. The eggs are ingested by Potamopyrgus. The eggs hatch, and during maturation the parasite reproduces asexually, producing hundreds of metacercarial cysts. In the process the parasite sterilizes the snail. The life cycle is completed when infected snails are eaten by waterfowl.

\section{Methods}

Gobiomorphus cotidianus were collected in each of four years from Lake Alexandrina on the South Island of New Zealand $\left(170^{\circ} 27^{\prime} \mathrm{E}, 43^{\circ} 56^{\prime} \mathrm{S}\right)$. In February 1994, I collected fish (using dipnets) from the lake predominantly between 13:30 and 15:00. In February of 1995, I performed the collections starting at 09:00 and 14:00, and in January of 1996, the collections were made starting at 09:00, 14:00, and 22:00. In January of 1997 fish were collected on several different days between the hours of 14:00 and 15:00. These collections did not take more than one hour to perform. I preserved the fish in $70 \%$ ethanol at the time of collection. Before dissection I recorded the length and gape of each fish. The gut of each fish was completely removed and the contents were quantified. I measured the length of each ingested snail using an ocular micrometer. Any snail greater than $2.0 \mathrm{~mm}$ in length was dissected and its gender, brooding condition, and parasite prevalence were recorded (snails less than $2.1 \mathrm{~mm}$ in length have never been found to be infected). I identified the parasites using the descriptions provided by Winterbourn (1973).

Kruskal-Wallace one-way ANOVA tests were used to compare the number of snails found in fish guts of the morning and evening samples to the number of snails found in the fish guts of the afternoon samples for each day in 1995 and 1996. Only fish from these years were used to assess the time snails were eaten, because fish collected from the other two years were sampled only in the afternoon. I also used the test to compare all sample times across years. The non-para- 
Table 1. Analysis of the number of snails found in fish guts by time of day using Kruskal-Wallis one-way ANOVA. The afternoon samples were compared independently to the morning and evening samples in 1996. In all comparisons DF $=1$ except for the final test grouping the data across years, where $D F=2$.

\begin{tabular}{|c|c|c|c|c|c|c|c|c|}
\hline \multirow[t]{2}{*}{ Year } & \multicolumn{2}{|c|}{ Morning } & \multicolumn{2}{|c|}{ Afternoon } & \multicolumn{2}{|c|}{ Evening } & \multirow[t]{2}{*}{$\chi^{2}$} & \multirow[t]{2}{*}{$P$} \\
\hline & $N$ & Mean rank & $N$ & Mean rank & $N$ & Mean rank & & \\
\hline 1995 & 85 & 57.79 & 46 & 81.17 & & & 14.26 & $<0.001$ \\
\hline \multirow[t]{2}{*}{1996} & 40 & 52.86 & 81 & 65.02 & & & 4.19 & 0.041 \\
\hline & & & 81 & 60.03 & 35 & 54.96 & 0.69 & 0.408 \\
\hline $1995-96$ & 125 & 126.80 & 127 & 162.07 & 35 & 139.84 & 14.69 & $<0.001$ \\
\hline
\end{tabular}

metric test was used because the numbers of snails found in fish guts within sample times were not normally distributed.

The above tests assume that snails collected at one time period do not remain in the fish gut to the next time period. To test this assumption, I collected fish in the same manner as described above but from a different site. I preserved half of the collected fish immediately. The other half were kept alive in a $20-1$ bucket in the absence of snails for an additional $3.5 \mathrm{~h}$ before they were preserved. The fish were dissected, and I recorded the number of fish with snails remaining in the guts for each group. I compared the ratio of fish with snails in their guts to fish without snails in their guts for the fish preserved immediately versus fish preserved $3.5 \mathrm{~h}$ later using a chi square test.

The fish used in this study were collected from two different sites in Lake Alexandrina, "Campsite" and "West Bay" (Jokela and Lively 1995). The fish collected in 1994 and 1997 were from Campsite, and the fish collected in 1995 and 1996 were collected from West Bay. To compare the infection rate of snails found in fish guts to the snail population at large, I collected snails from the population at large from each site at the same time the fish were collected. At least 250 snails were collected from the population at large each year by sampling rocks within the lake and removing all of the snails found on them. The snails' lengths were measured and they were dissected, noting gender, brooding condition, and type of parasite. The infection rate of the snails found in the fish guts was compared to the infection rate of the snails from the population at large by using multiple logistic regression. The probability of a snail being infected was predicted to be a function of the variable's population (where the snail was collected from: population at large or fish gut), year of collection, and snail size. Size is an important variable because the probability of infection increases with snail size in this population (Jokela and Lively 1995) and the size distribution of the snails found in the fish guts was different from the size distribution of the snails from the population at large (Levri unpubl.). The significance of the main effects of population (eaten by fish or not eaten), size of snail, and year of collection was determined by subtracting the -2 log- likelihood value from the logistic regression analysis output that included the term as a factor in the model from the $-2 \log$-likelihood value of the analysis output from a model with the term omitted. This produces a log-likelihood ratio statistic whose distribution is approximately chi-square with degrees of freedom equal to the number of parameters tested (Hosmer and Lemeshow 1989). The logistic regression analyses were performed using SPSS software using the logistic regression procedure (Norusis 1990). Only the main effects terms were included in the model. A model including the interaction terms results in individual regressions for all populations. Since only one individual was found in infected snails from fish guts, the interaction terms could not be reliably estimated. Without interaction terms, I am assuming that the resulting regression curves are similar in shape, which is likely to be a safe assumption.

\section{Results}

Only in 1995 and 1996 were the fish sampled over time; thus, only these data were used to assess when the fish were feeding. A total of 287 G. cotidianus was sampled in 1995 and 1996 yielding a total of 591 Potamopyrgus in their guts. Of the 591 snails, all snails greater than $2.0 \mathrm{~mm}$ in length were dissected to determine infection status (previous studies utilizing over 20000 snails have never yielded a Microphallus-infected snail less than 2.1 $\mathrm{mm}$ in length). The size distribution of fish was skewed towards smaller individuals (Levri unpubl.). The number of snails found in the fish guts ranged from 0 (the most common observation) to 38 . The mean standard length of the fish was not significantly different among any of the samples ( $P>0.05$ in all cases). Thus, the size of a fish was not used as a factor in the statistical analyses.

In 1995, fish had significantly more Potamopyrgus in their guts in the afternoon than in the morning $(P<$ 0.001 , Table 1, Fig. 1). I observed the same trend in 1996 , but the difference was only marginally significant $(P=0.041)$. When I grouped data across years, there were significantly more snails found in fish guts in the afternoon samples than in the morning or evening 
(Table 1). In the 27 cases where the number of snails in fish guts was 11 or more, 23 were from the afternoon, 2 were from the morning, and 2 were from the evening. In fact, all 10 cases where there were more than 16 snails in one fish were from afternoon samples.

Fish preserved immediately after collection were more likely to have snails in their guts than fish isolated and preserved $3.5 \mathrm{~h}$ after they were collected (Fig. 2). Fifteen of 25 fish had snails in their guts at the time of collection; only five of 25 had snails in their guts $3.5 \mathrm{~h}$ after collection $\left(\chi^{2}=8.33, P=0.004\right)$. In the fish that were isolated for $3.5 \mathrm{~h}$, all of the snails were clustered in the terminal portion of the digestive tract. Thus, it is likely that they would have soon been expelled, especially if the fish had been foraging freely in the interven-
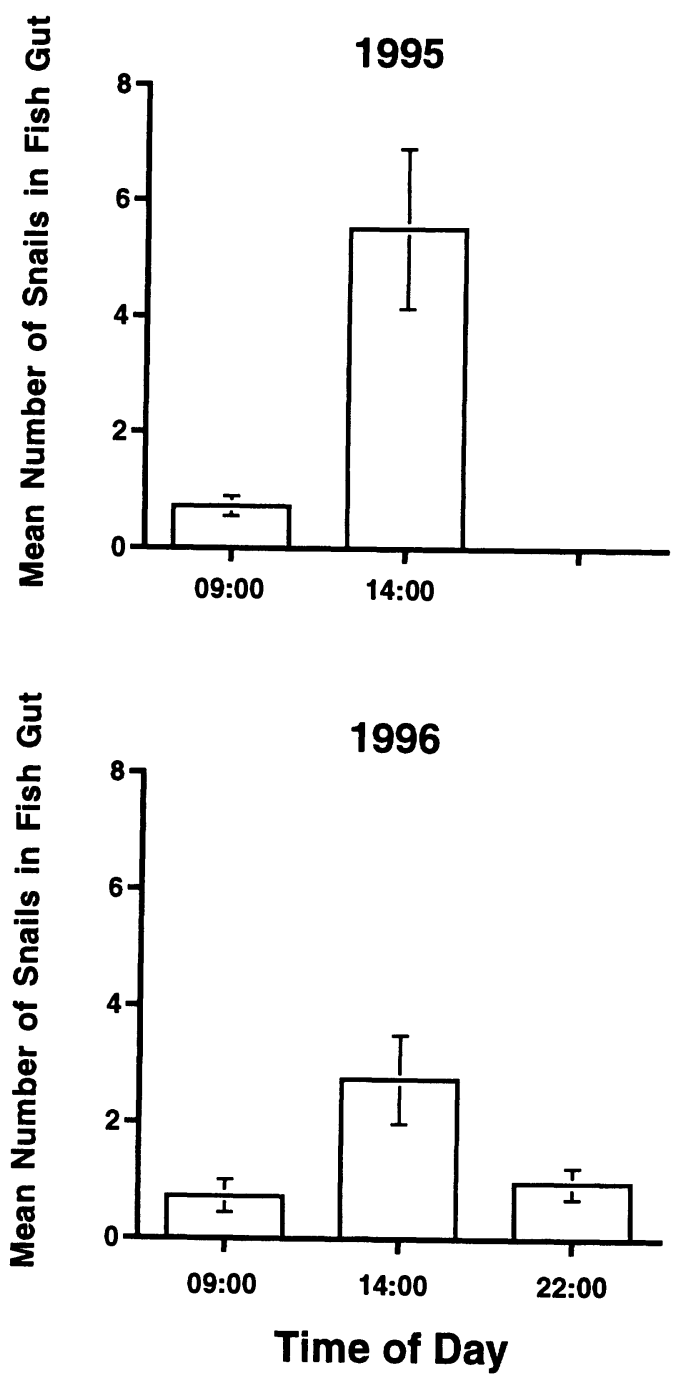

Fig. 1. The mean number of snails found in the fish guts by time of day for 1995 and 1996. There were significantly more snails found in the fish guts in the afternoon compared to the early morning in 1995, and the same trend was found in 1996 (Table 1). Vertical bars are standard errors.

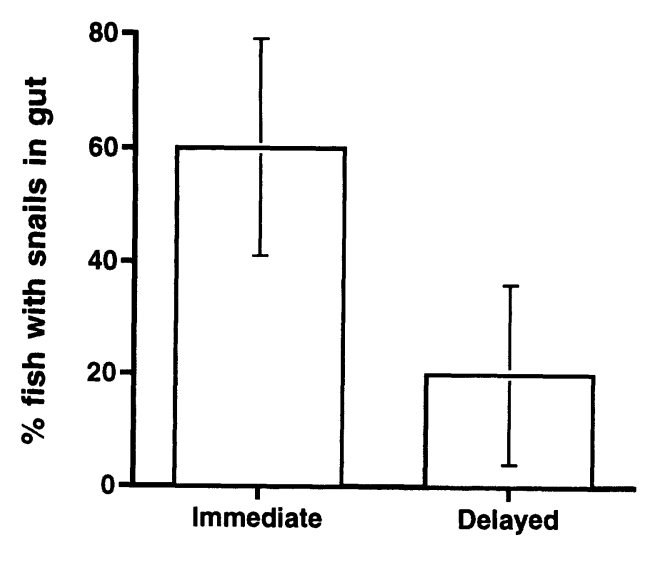

Time of Preservation

Fig. 2. The percentage of fish with snails in their guts preserved immediately at the time of collection and delayed $3.5 \mathrm{~h}$ post collection. Most fish appear to eliminate the consumed snails within $3.5 \mathrm{~h}$. Error bars are $95 \%$ confidence intervals.

ing time. Since the snails seem to remain in the fish guts for about $4 \mathrm{~h}$, the samples collected in the morning, afternoon, and evening represent the foraging habits of the fish for the $4 \mathrm{~h}$ before their collection. Therefore, most if not all snails from the fish collected at 14:00 are independent from the snails from fish collected at 09:00.

If infected snails are less likely to be eaten by fish than uninfected snails, fewer infected snails should be found in the fish guts than expected from a random sample of the population at large. There were 104 snails found in fish guts from 1994-1997 that were greater than $2.1 \mathrm{~mm}$ in length, and, thus, could have potentially been infected by Microphallus. I found only one of these snails to be infected by Microphallus (Fig. 3). The logistic regression analysis (of snail size on probability of infection) using data from morning, afternoon, and evening samples for snails in the guts compared to

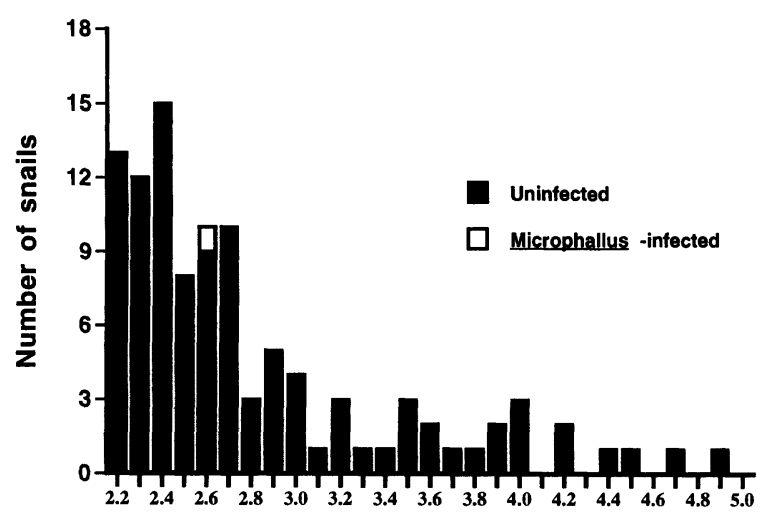

Size $(\mathrm{mm})$

Fig. 3. The size distribution of uninfected and Microphallusinfected snails found in the fish guts. The size distribution is skewed toward smaller snails. The only infected snail found was $2.6 \mathrm{~mm}$ in length. 
Table 2. Logistic regression analysis of the probability of infection predicted by snail population (eaten or uneaten), size, and year of collection. The change in the -2 log-likelihood value follows appoximately a chi-square distribution if the hypothesis of no effect is true.

\begin{tabular}{|c|c|c|c|}
\hline Term & $\begin{array}{l}\text { Change in }-2 \text { log-likelihood value if } \\
\text { term removed from the analysis }\end{array}$ & $\mathrm{df}$ & $P$ \\
\hline \multicolumn{4}{|c|}{ Morning and evening samples only } \\
\hline Population & 2.16 & 1 & 0.14 \\
\hline Size & 23.53 & 1 & $<0.001$ \\
\hline Year & 4.89 & 3 & 0.18 \\
\hline \multicolumn{4}{|c|}{ Afternoon samples only } \\
\hline Population & 11.45 & 1 & $<0.001$ \\
\hline Size & 28.65 & 1 & $<0.001$ \\
\hline Year & 4.53 & 3 & 0.21 \\
\hline \multicolumn{4}{|l|}{ All samples } \\
\hline Population & 11.51 & 1 & $<0.001$ \\
\hline Size & 28.41 & 1 & $<0.001$ \\
\hline Year & 4.70 & 3 & 0.20 \\
\hline
\end{tabular}

uneaten snails yielded a significant effect of population $(P<0.001$, Table 2$)$. Thus, snails found in fish guts are significantly less likely to be infected by Microphallus than snails from the population at large. The predicted relationship between the probability of infection and snail size between eaten and uneaten snails is presented in Fig. 4. The prediction that fewer infected snails should be found in fish guts than due to chance was expected to be dependent upon the time of day that the fish were collected. When only snails found in fish guts from afternoon samples are compared to the population infection rates, similar results are found $(P<0.001$, Table 2). A total of 64 snails large enough to be infected were collected from the afternoon-collected fish. Of these, no snails were found to be infected. For the 40 snails large enough to be infected found in the morning and evening samples, one infected snail was found. The results yielded no significant effect of population $(P=0.14$, Table 2$)$. In all three comparisons a significant effect of size of snail was found, indicating that the probability of infection changes with snail size.

\section{Discussion}

The results of this study show that the fish G. cotidianus feeds on $P$. antipodarum predominantly in the late morning and early afternoon hours (Fig. 1). This peak in fish foraging corresponds with the movement of infected snails from the top to the bottom of rocks (Levri and Lively 1996). Thus, the behavioral change associated with the parasite would seem to reduce the probability of encounter between infected snails and fish.

To compare the number of snails found in fish guts from different times of the day, the samples must not overlap. Said in another way, there should be little chance that snails in fish guts in the afternoon sample were eaten in the early morning. The results show that there were significantly fewer fish with snails in their guts for fish preserved $3.5 \mathrm{~h}$ after they were collected than for fish preserved immediately after collection (Fig. 2). All snails found in fish guts, where preservation was delayed $3.5 \mathrm{~h}$, were found in the terminal portion of the gut. Thus they were likely to be eliminated in the near future. Anecdotally, in two instances where I have been able to feed these snails to the fish in the lab, the snails passed through the fish in under 3.5 $h$. Since I performed the fish collections in the morning, afternoon, and evening at intervals of at least 4 to $5 \mathrm{~h}$, it is unlikely that snails eaten before the morning collection times were a significant portion of the snails found in the afternoon samples.

If moving to the bottom of the rocks in the late morning reduces the probability of the snail being eaten by fish, fewer infected snails should be observed in the diet of fish than is expected based on the infection rate of the snails in the population at large. Comparing the infection rate of snails found in fish guts to that of the population at large within each year of collection revealed that significantly fewer infected snails were eaten by fish than expected by chance (Fig. 4, Table 2). Infected snails should have had the lowest probability of being found in fish in the afternoon if the parasiteinduced behavior reduces the probability of predation. When only snails from fish caught in the afternoon samples were used, fewer infected snails than expected were also found in the fish guts $(0$ infected out of 64 snails). Since Microphallus-infected snails are on the top of the rocks in the early morning and evening (Levri and Lively 1996) there should not necessarily be fewer than expected infected snails in the fish guts at these times. The data ( 1 infected snail out of 40) are consistent with this idea, but since only one infection was found, little should be inferred from a single occurrence.

Another explanation for the absence of infected snails in the fish diets might be that infected snails are 


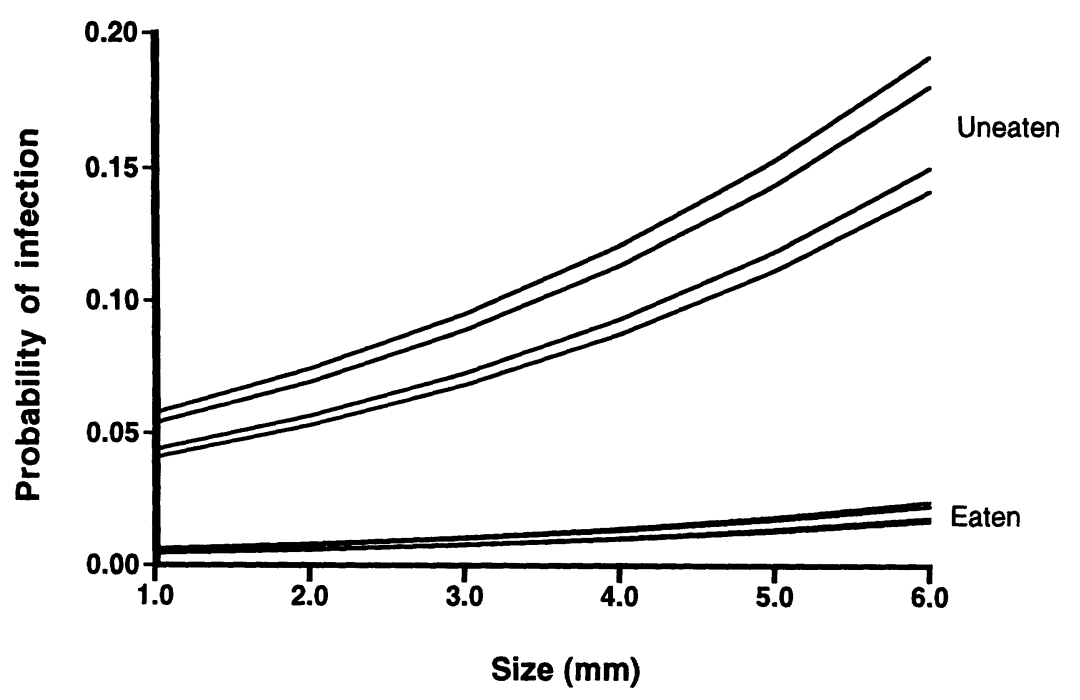

Fig. 4. The predicted relationship between snail size and probability of infection for snails that were eaten by fish and snails from the population at large using logistic regression analysis. Each of the four curves in the uneaten and eaten groups represents the data from one of the four years of the study. Infected snails are less likely to be found in fish guts than is expected by chance. Thus, the behavior induced by Microphallus may decrease the probability that infected snails will be eaten by an unsuitable fish host.

distasteful to fish. Parasites and pathogens have been demonstrated to increase unpalatability in their hosts in some cases (e.g. Clay et al. 1985). An increase in distastefulness could be advantageous for the parasite if it decreases the probability of predation by non-host predators. Such an alteration could be a physiological by-product of infection, or it could be an example of parasites adaptively altering the phenotype of the host. In Potamopyrgus infected by Microphallus distastefulness could decrease the probability of ingestion by non-host predators (fish). However, both fish and waterfowl ingest the snail without crushing it; thus in order for the snail to be distasteful to fish, the snail would have to excrete a chemical. If infected snails did excrete a distasteful chemical, it would likely be distasteful to waterfowl as well as fish, which could decrease the transmission efficiency to the final host. Therefore, I believe that a parasite-induced increase in distastefulness in Potamopyrgus is unlikely. In any case, this alternative hypothesis remains a possibility.

The foraging of the fish would also seem to explain the foraging behavior patterns of uninfected snails. In a previous study, brooding females, males, and juveniles retreated to the bottom of the rocks in the morning and did not come back to the top until evening (all classes of snails, infected and uninfected, were found to forage at night) (Levri and Lively 1996). It would appear that these classes of snails behave in this way to reduce the risk of fish predation. Only non-brooding females remain on top of the rocks throughout the day (it appears that they are trading off the risk of predation with the resources necessary to initiate the next brood [Levri and Lively 1996]). Snails infected by transmissible Microphallus remain on top of the rocks longer in the morning while waterfowl are feeding. Thus, it would appear that the parasite manipulates the snail in the early morning to behave more similarly to non- brooding females to increase the chance of being eaten by a duck. Then in the late morning the parasite "turns off" its manipulative effect or induces behavior similar to brooding females which serves to decrease the probability of predation by fish. Parasites that are not yet transmissible do not induce the snails to be on top of the rocks in the early morning (Levri and Lively 1996). The behavior characteristic of snails infected with nontransmissible parasites may result in a decreased probability of the snail being eaten by all predators, as snails infected by non-transmissible parasites seem to stay on the bottom of the rocks throughout the day.

Many studies have concluded that the behavioral effects of a parasite on its intermediate host facilitate transfer of the parasite through the food chain to the next host in the life cycle (Holmes and Bethel 1972, Dobson 1988, Moore and Gotelli 1990). The results from these studies suggest that the foraging habits of a secondary host can be a selective force on the manipulative strategy of a parasite. The present result is the first example, to my knowledge, that suggests that a predator that is not the final host may be an important selective force on the manipulative strategy of a trophically transmitted parasite. Thus the manipulative strategy of this parasite would appear to be selectively influenced not only by the foraging habits of the final host, but also by those of a more common, non-final host predator.

Acknowledgements - I thank M. Dybdahl, A. Krist, and S. Reymann for help in the lab and the field, B. Flury for statistical advice, and M. Levri, C. Lively, C. Nelson, and D. Wiegman for helpful comments on previous versions of the manuscript. I am indebted to the Zoology Dept at the Univ. of Canterbury in Christchurch, New Zealand for their continued support, including I. McLean, J. Van Berkel, M. Winterbourn, and especially J. McKenzie. This study was supported by an NSF grant to C. Lively (BSR-9008848), and an NSF dissertation-improvement grant (DEB-9509286), and by grants 
from the Indiana Univ. Research Training Grant in Animal Behavior, and the Indiana Academy of Science.

\section{References}

Bethel, W. M. and Holmes, J. C. 1974. Correlation of development of altered evasive behaviour in Gammarus lacustris (Amphipoda) harboring cystacanths of Polymorphus paradoxus (Acanthocephala) with the infectivity to the definitive host. - J. Parasitol. 60: 272-274.

Clay, K., Hardy, T. N. and Hammond, A. M., Jr. 1985. Fungal endophytes of grasses and their effects on an insect herbivore. - Oecologia 66: 1-5.

Dobson, A. P. 1988. The population biology of parasiteinduced changes in host behaviour. - Q. Rev. Biol. 63: $139-165$.

Granovitch, A. I. 1992. The effect of trematode infection on the population structure of Littorina saxatilis (Olivi) in the White Sea. - In: Grahame, J., Mill, P. J. and Reid, D. G. (eds), Proceedings of the third international symposium on littorinid biology. The Malacological Society of London, London, pp. 255-263.

Haynes, A. and Taylor, B. J. R. 1984. Food finding and food preference in Potamopyrgus jenkinsi (E. A. Smith) (Gastropoda: Prosobranchia). - Arch. Hydrobiol. 100: 479-491.

Holmes, J. C. and Bethel, W. M. 1972. Modification of intermediate host behaviour by parasites. - In: Canning, E. U. and Wright, C. A. (eds), Behavioural aspects of parasite transmission. Academic Press, New York, pp. $123-149$.

Hosmer, D. W. and Lemeshow, S. 1989. Applied logistic regression - Wiley, New York.

Hurd, H. and Fogo, S. 1991. Changes induced by Hymenolepis diminuta (Cestoda) in the behaviour of the intermediate host Tenebrio molitor (Coleoptera). - Can. J. Zool. 69: 2291-2294.
Jokela, J. and Lively, C. M. 1995. Spatial variation in infection by digenetic trematodes in a population of freshwater snails (Potamopyrgus antipodarum). - Oecologia 103: 509517.

Levri, E. P. and Lively, C. M. 1996. The effects of size, reproductive condition, and parasitism on foraging behaviour in a freshwater snail, Potamopyrgus antipodarum. - Anim. Behav. 51: 891-901.

Lively, C. M. 1987. Evidence from a New Zealand snail for the maintenance of sex by parasitism. - Nature 328: 519-521.

McDowall, R. M. 1990. New Zealand freshwater fishes: a natural history and guide - Heinemann Reed, Wellington.

Moore, J. and Gotelli, N. J. 1990. A phylogenetic perspective on the evolution of altered host behaviours: a critical look at the manipulation hypothesis. - In: Barnard, C. J. and Behnke, J. M. (eds), Parasitism and host behaviour. Taylor and Francis, London, pp. 193-233.

Norusis, M. J. 1990. SPSS advanced statistics user's guide. SPSS, Chicago.

Poulin, R., Curtis, M. A. and Rau, M. E. 1992 Effects of Eubothrium salvelini (Cestoda) on the behaviour of Cyclops vernalis (Copepoda) and its susceptibility to fish predators. - Parasitology 105: 265-271.

Tierney, J. F., Huntingford, F. A. and Crompton, D. W. T. 1993. The relationship between infectivity of Schistocephalus solidus (Cestoda) and anti-predator behaviour of its indermediate host, the three-spined stickleback, Gasterosteus aculeatus. - Anim. Behav. 46: 603-605.

Winterbourn, M. J. 1970. The New Zealand species of Potamopyrgus (Gastropoda: Hydrobiidae). - Malacologia 10: 283-321.

- 1973. Larval Trematoda parasitizing the New Zealand species of Potamopyrgus (Gastropoda: Hydrobiidae). Mauri Ora 2: 17-30.

- and Fegley, A. 1989. Effects of nutrient enrichment and grazing on periphyton assemblages in some spring-fed, South Island streams. - N.Z. Nat. Sci. 16: 57-65. 